\title{
16
}

\section{International justice}

\author{
David Boucher
}

\section{Introduction}

Is justice intra-national or international, localised or globalised, communitarian or cosmopolitan, universal or particular, in its scope? Do richer countries have a duty to help poorer countries and, if so, is this duty a matter of charity or justice, or both? Answers to these questions are often dependent upon an answer to a prior question: are state boundaries morally arbitrary and, if so, do we have a responsibility to help the less well off beyond these borders? A whole range of positions are taken which often cut across the cosmopolitan-communitarian divide favoured by such theorists who work within the field of international relations as Chris Brown, Janna Thompson, Charles Jones and Peter Sutch. ${ }^{1}$

Cosmopolitanism points to the justification of our moral principles as having a universal basis. For the cosmopolitan the existing social arrangements have no special status as the source of our value. The type of universal principles required is generated by three different sources of cosmopolitanism: Kantianism, utilitarianism and Marxism. Although utilitarianism is an entirely different moral theory from that of Kant, it is nevertheless cosmopolitan. Jeremy Bentham is, of course, the classic utilitarian. His theory is clearly cosmopolitan in that values are universal, and not the product of various particularistic communities. Each individual feels pleasure and pain and this is the basis of human values. Individuals have a basic duty to increase the happiness of humankind in general. The institutions of the family and state, for example, have claims on our duty because they promote the maximisation of the general happiness and not because they have priority over utility. Similarly, governments have a duty to promote the happiness of humankind even if this somehow damages the interests of its own citizens. The principle of the greatest happiness has to be the guide to what is right and wrong. In so far as international law is conducive to the general happiness it should be encouraged, and in so far as war is detrimental to the general happiness it should be discouraged. Nothing in Bentham's view has intrinsic value, except pleasure: everything, including the existence of states, has to be judged on their consequences. ${ }^{2}$ 
The central feature of communitarianism is that the source of value derives from the community, and that communities themselves are ethically significant. Individuals derive their meaning in life from, and are constituted by, the political communities they inhabit. Such theorists as Frost and Brown call themselves constitutive theorists in order to get away from the connotation that communitarianism has of giving priority to the nation or state, but also in order to jettison the metaphysics associated with Hegelianism. Brown, like Frost, relies on Hegel for his account of the development of individuality. Brown quite explicitly rejects Hegelian metaphysics and presents us with what he calls a 'demythologised' version. ${ }^{3}$ Through the family, the individual develops a personality and sense of belonging in the world based on unconditional love. Taking responsibility for one's projects in the context of civil society, and participating in the world of private property, the market and the institutions which sustain them, constitutes a further stage in the development of consciousness. This stage, however, places individuals in competition, and in civil society they experience the law as an external imposition and constraint. More consciously developed individuals come to internalise the law and appreciate others as fellow citizens and not competitors. The rationale of the modern ethical state, based on the principles of the rule of law and the separation of the powers, is to bring about this transformation in consciousness.

Rather than as polar opposites the various versions of cosmopolitanism and communitarianism in international relations are best conceived as occupying places on a scale, the ends of which are not absolute zero and infinity, but a universalism or cosmopolitanism which is not completely devoid of communitarianism or particularism, and a particularism which accommodates universalism. Neither is insensitive to the concerns of the other. One of the best syntheses is that of Onora O'Neill whose concerns are cosmopolitan-based duty rather than rights. This enables her better to incorporate the particularist special obligation virtue ethics which motivate communitarians. This chapter, therefore, surveys the cosmopolitan and communitarian positions before turning to her synthesis of the two.

\section{Cosmopolitanism/universalism}

The seminal starting point in discussions of distributive international justice which transcends state borders, and denies the nation as an ethically relevant factor in such considerations, is the position of Peter Singer. ${ }^{4}$ Singer's argument implicitly covers both humanitarian aid, typically generated by a sense of solidarity when natural disasters dramatically threaten lives, and what is called development aid, which contributes towards programmes of self-sustainment such as establishing irrigation systems, sinking wells, transforming farming practices and so on. The programmes are less visible than emergency aid, but of more importance in the long run. 
As a utilitarian, the alleviation of harm and suffering is crucial to his line of reasoning, although he denies that his argument relies upon utilitarianism. He starts with the assumption that suffering and death caused by a lack of food, shelter and medical care are bad, and that if it is in our power to prevent it from happening without sacrificing something of comparable moral significance then we ought to do it. The principle requires us only to prevent what is bad, not to promote that which is good. Even in a modified form, which requires us only to prevent very bad things from happening without having to sacrifice anything of moral significance, the consequences are deceptively far reaching. There are two momentous implications. First, distance and proximity are not morally relevant factors: 'If we accept any principle of impartiality, universalizability, equality, or whatever, we cannot discriminate against someone merely because he is far away from us'..$^{5}$ Second, it makes no significant moral difference whether I alone, or millions of other people, are in the same position to prevent the harm, which in Singer's examples are saving a drowning child or helping Bengali famine victims. Put starkly, neither geography nor numbers lessen our obligation to prevent the harm. This means that giving money to, say, the Bengali relief fund is a matter of duty rather than charity, and that the act is not supererogatory, that is something that is good to do, but not morally reprehensible if I fail to do it.

How much are we obliged to give, and is it a matter of duty rather than charity? On the strong version, we should help others up to the level of marginal utility, that is the point at which by giving more we would cause a comparable amount of harm to ourselves or our dependants. On the moderate version, where we are required to prevent bad things happening without sacrificing anything of moral significance, we would still witness a considerable transformation in society because expenditure upon trivia, which the consumer society encourages, would be morally indefensible.

Both the strong and the moderate versions require us when saving lives is at issue to invoke a standard of absolute poverty, where the lack of food and resources lead to malnutrition and death, or when life is threatened by the comparatively rare occurrence of extreme famine and natural disaster. If, however, we are to take a more relaxed standard than absolute poverty, where not only life itself, but the quality of life should be a concern, then we invoke some notion of relative poverty, where, for example, eastern Europeans are well-off in comparison with Africans, but poor in comparison with western Europeans. It is a standard that does not signify any particular level of suffering or death. ${ }^{6}$ The strong version of Singer's case, the one that he prefers, would in fact commit us to relieving relative poverty to the point where we are almost as poor as the recipients. Even the weaker version, in his opinion, would lead to a significant shift of resources.

The argument, however, lacks a time dimension, and suffers from an inability to assess comparative benefits and costs. The cost of the QE2 was indeed immense when compared with the suffering that may have been relieved at the 
same cost. The jobs provided, the additional allied businesses that relied upon the venture, and the multiplier effect in the European economy may well mean that in the long run more has been given to charity through governments and individual contributions by prolonging the life of the ship building industry than if it had been allowed to sink into decline.

More fundamentally, Hare's objections to intuitive morality apply to Singer's type of argument. Singer is not offering a moral theory as such, but presenting us with something that it is said everyone would agree to, and if we agree to it, then we must agree to something else because the principle is the same. Singer gives the example of saving a drowning child at the expense of getting one's trousers muddy, and extends the obligation felt in this situation to saving a starving Bengali 10,000 miles away. ${ }^{7}$ What is presupposed is, first, that something that it is said everyone would agree to, ought to be agreed to, and second, that the principles really are the same. This would entail a scrupulous examination of what the principle is, but it gives us no reason why we should accept it, and not reject both judgements.

Garret Hardin raises a different kind of objection. Can it be morally right to redistribute resources if the benefits are far from evident? Redistributing benefits may have an affect on what is distributed. Hardin argues that the world is like a lifeboat unable to take all those who want to be saved. Some people are in it and others are in the water wanting to get in. If access is not restricted everyone will sink, and no one will benefit. ${ }^{9}$ This is a metaphor, but like all metaphors may be misleading. What Hardin denies is the right of the poor to a share of the resources of richer countries, and he casts doubt on the moral efficacy of charitable redistribution. What he assumes is that the benefit is fixed and if spread too thinly will cease to be a benefit. Again, the time factor needs to be considered. The world does not have a fixed capacity, nor can we predict the effect of redistribution on population growth, nor the effect of population growth on economic sustainability. There is in fact much evidence to suggest that once a society has developed sufficiently to provide adequate food, basic health care and security in old age, increasing population trends level out or decline. ${ }^{10}$ Indeed, poverty may increase populations on the principle that one extra mouth to feed equals two extra hands. In addition, if the benefit can be diminished by being spread too thin, it can also be increased by being spread wisely. His argument is based on 'the law of diminishing returns' which states that when there are small increases in a factor of production, other factors remaining constant, say, adding labourers to a fixed acreage of land, the resulting increases in output will after a certain point progressively get smaller. However, this consideration has to be balanced against the law of marginal utility. The additional amount of benefit I receive from each additional unit of value diminishes to the point where negative utility may be achieved. The amount of utility I get from, say, each additional ice cream diminishes until I make myself sick. What is of negative benefit to me will on someone else's utility curve produce positive benefits. For example, if I give my fifth ice cream in a relatively short 
period to someone who is starving the utility derived from it by the other person is much greater than mine.

Hardin's position denies the efficacy of both charity and duties of justice. The distinction between duty and charity which was made by Peter Singer is applied differently by Gordon Graham. Graham contends that the recognition that everyone in the world has basic rights to the necessities of life can generate nothing more than imperfect obligations, that is, claims upon everyone, but upon no one in particular. The right to social justice requires and assumes a government or state as the distributor, capable of enforcing contributions and deterring free-riding, but at the international level no such authority exists. Basic needs are best met out of a sense of charity rather than as a matter of redistributive justice which stops at the borders of the state. ${ }^{11}$

Brian Barry extends Singer's and Hardin's distinction further in suggesting that acting from considerations of justice is different from, but not incompatible with acting out of a sense of humanity. Accepting Singer's argument, Barry contends that we have an obligation to give humanitarian aid to the poor, but on the question of how much he suggests that no hard and fast rule can be determined. ${ }^{12}$

Humanitarian obligation is not derived from justice, but this does not mean that it is an act of generosity or that it should be left to the discretion of the individual. The principles relating to humanity are goal based in that they are concerned with the well-being of individuals and have to do with questions of welfare, freedom from poverty and disease, and provision for satisfying basic needs. In Barry's view, the duty of humanity is a matter of doing good. A humanitarian tax may be levied and distributed through international agencies to promote goal-orientated projects. Humanitarian redistribution would as now be earmarked for specific use and its receipt would be conditional. The control of the resources would be in the hands of international bodies such as the International Monetary Fund or the World Bank.

On considerations of justice, however, the 'distribution of control of resources would actually be shifted ${ }^{13}$ In other words, the transfer of resources would not depend upon the use made of them. Humanitarian aid may justifiably have strings attached in order to attain the desirable state of affairs it is designed to bring about. By contrast, justice is not concerned with these things at all. Justice relates to a set of wholly different principles which have to do with power. It is partly about who is entitled to what. Barry's point is effectively this: it makes little sense to argue about what a state should do with its own resources, for example, how it should distribute various benefits to the poor, until it is determined what those resources are. In Barry's argument, they include a right to a share of the income from the world's natural resources. ${ }^{14}$ If we have a basically just international distribution, then the need for humanitarian aid is reduced to responding to extraordinary problems relating to epidemics, famine, droughts, floods and earthquakes.

The principles of international justice have to do with resources in the broadest sense, including non-material resources which incorporate issues of rights 
- such as acting without interference from others, limiting the actions of others and regulating changes to the non-human environment. Justice, then, has to do with the distribution of control over material resources and the principles governing how control ought to be allocated. At this level of abstraction the principles of allocation are supplemented with the principle of equal liberty which relates to control over non-material resources. The fortuitous allocation of natural resources throughout the world is morally arbitrary, and the populations of the various countries can hardly be held responsible for their good or bad fortune, and the benefits or miseries which ensue..$^{15}$ The assumption is that benefits from favourable natural resource allocation are 'unearned' and that people have no exclusive right to the benefits they obtain from them.

The principle of the strong powers exploiting the weak by laying claim to their resources has been somewhat weakened by various conventions and United Nations resolutions to the effect that states have absolute sovereign control over their natural resources. This morality of the lottery is preferable to the morality of control and exploitation. However, it is less acceptable to seeing the world's natural resources as the common possession of the world's population as a whole. International justice, Barry contends, is not a matter of charity. The redistribution of resources raised through an international resources tax is a matter of entitlement. Therefore, it must be transferred unconditionally to the recipient countries. By contrast, Rawls dismisses out of hand the relevance of the arbitrariness of resource distribution to international justice. A country's fortunes, he contends, are due more to its political culture and the virtues of its people than to natural resources. ${ }^{16}$

Charles Beitz and Thomas Pogge postulate a form of cosmopolitanism that does not depend upon the idea of a universal political community of humankind. They are concerned to emphasise the interdependence of states, and the effects that each has upon others, many of which have moral significance. Given these effects can be both good and bad, there is a need for some form of co-operation and regulation. They subscribe to the Kantian point that just institutions must be established among all those whose actions can impact upon each other. Beitz's argument for applying the Rawlsian difference principle to the international context is essentially that the extensive global system of trade, or complex interdependence, which is part of the conventional wisdom of international relations, constitutes a worldwide co-operative scheme in which every country is implicated. ${ }^{17}$ Rawls himself denies that the world constitutes a common co-operative enterprise, sufficient to qualify for considerations of distributive justice in the same way as bounded communities. Because there is no global society engaged in a co-operative enterprise, there is no co-operative surplus for which principles of distribution must be found. Although, more recently, Rawls has conceded that there is a case for the just distribution of basic liberties, and agrees with the aims of neo-Rawlsian cosmopolitans, such as Beitz and Pogge, ${ }^{18}$ of attaining liberal institutions, securing human rights and providing for basic needs in accordance with what he 
calls a 'duty of assistance', he does not agree with the principles they present for redistributive justice. ${ }^{19}$

Beitz distinguishes between a resource distribution principle, which applies when states are self-sufficient and where inequalities arise from uneven resources, and a global distribution principle. The latter arises when there are flows of goods and services from one country to another leading to co-operative surpluses for which an international difference principle may be invoked. Beyond the duty of assistance, which responds to gross injustices and inequalities, Rawls cannot see the appeal of the global principle because it posits no determinate target and is essentially open-ended. Its consequences, he suggests, would be unwelcome because it would be unacceptable to subsidise choices. ${ }^{20}$ If two liberal or decent countries of equal resources choose different paths of development, the one industrialisation and increased real saving, while the other prefers more traditional ways of living, why when vast inequalities of wealth appear should the former subsidise the latter through taxation?

Rawls's duty to assist does have a target and a cut off point. The target is burdened societies that are too poor to develop their own just institutions and equality of liberty, and the purpose of assistance to provide primary goods for basic needs is to raise a people to the point of establishing such institutions and to become capable of making their own choices. Such assistance need not take the form of redistributive justice, and it should not be assumed that giving money, although this is essential, will redress fundamental political and social injustices. In this respect change, is more likely if assistance is tied to respect for basic human rights. Rawls's criticism of Beitz is equally applicable to Steiner's argument for international distributive justice. Steiner deduces two different types of rights from the fundamental right to equal freedom. The first is the right to self-ownership, and the second to an equal share of natural resource values, the value being calculated by subtracting the value added by 'labour embodying improvements'. Steiner is elaborating upon the notoriously ambiguous Lockean proviso to leave as much and as good for everyone when appropriating land. Steiner contends that 'the equality of each person's landvalue entitlement is necessarily global in scope' ${ }^{21}$ In his view, we not only have a duty to desist from inflicting bodily harm on foreigners because of the principle of everyone's self-ownership, but also have a duty to pay their land value entitlement. The essential difference is this: Beitz, Pogge and Steiner wish to establish principles for equality of liberties, but in addition to Rawls press for a just distribution of resources.

\section{Communitarianism/particularism}

The later Rawls, because of his emphasis upon a political liberal conception of justice, has increasingly been allied to a communitarian or particularist position in which the elements of universalism derive from the principles which regulate communities or peoples. He can no longer be accused of having a view of 
the person as unencumbered or pre-social. For Rawls's theory personality depends upon both the formation and pursuit of a conception of the good, and on being embedded in the political culture of liberal democracy, or at least a well ordered hierarchical society that respects human rights, which are 'a special class of urgent rights'.22

He arrives at what these rights are by deploying the methods of ideal theory. International relations, for Rawls, rest on a second contract between what he calls 'peoples', or at least their representatives. Rawls is quite explicit about the fact that his Law of Peoples is an extension of a liberal conception of justice for domestic regimes. Rawls calls the result of his ideal theorising a realistic utopia, in that it takes people as they are, but develops laws and institutions that are as they may become. The resulting Law of Peoples applies not only to relations among liberal well ordered regimes, but also to decent hierarchical well ordered peoples, who, although not liberal, uphold human rights and respect basic liberties. They are not liberal because they support a comprehensive doctrine, whether it be political or religious, and those who do not adhere to it fail to enjoy the full range of citizenship rights, but do enjoy a basic minimum, including the security of acceptance of the rule of law.

A political conception of justice has recourse to those ideas which are immanent, or latent, in a democratic society's public political culture. The human rights endorsed by Rawls's political conception of justice operate on a different plane from those that arise from and are supported by comprehensive doctrines. This is something that Charles Taylor endorses in believing that there can be an overlapping consensus on basic human rights, but the reasons for valuing them may derive from very different comprehensive doctrines. ${ }^{23}$

Rawls specifies what these human rights are: they are not parochial or peculiarly liberal, nor do they depend upon any comprehensive doctrine or philosophical theory of human nature. His conception of human rights is very like that put forward by the British Idealists over a century ago. They are those rights that have come to be recognised as essential for social co-operation, and for promoting the common good. In fact they are universal, subscribed to by decent peoples all over the world, and ought to be by those who do not. Rawls places the responsibility for sustaining human rights firmly in the hands of governments. They are rights relating to basic needs such as the right to life, and to the means of subsistence and security, including the protection of ethnic minorities against genocide and ethnic cleansing, and to freedom from slavery. In addition, he advocates basic political rights such as liberty of conscience, equality before the law, and the right to personal property. ${ }^{24}$ Human rights fulfil three roles: they are the necessary conditions of the decency of a society's institutions and legal system; upholding them averts any question of justifying foreign intervention in a people's domestic affairs, such as trade sanctions or military force; and, they circumscribe the limits of reasonable pluralism among peoples. ${ }^{25}$

Others give even greater emphasis to the ethical significance of a particular community or nation. It is quite common among those who deny the ethical 
significance of a cosmopolitan community to argue that much closer ties of kinship or group solidarity generate the obligations we have to others. Both Walzer and Miller, for example, argue that there is no consensus that the needs of other humans, simply in their capacity as humans, impose any obligations of justice upon us, indeed there is insufficient consensus on what counts as a need. Typical of writers from the British Idealists to Walzer and Rorty, Miller does not see compassion exhausted by an enhanced sense of justice towards one's compatriots, one's family or co-religionists. On the contrary, it is equally as likely that as long as conflicting demands are not imposed our caring for outsiders will strengthen rather than diminish. ${ }^{26}$ Walzer makes a distinction between maximal and minimal morality, the latter residing in the former. Minimal morality is universal only to the extent that it is widely endorsed, not because it constitutes an objective reality. It is essentially the shared sum of overlapping outcomes which different moral codes have in common, without any suggestion that they have a common source. Maximal morality is embedded deeply in communities and is relative to one's cultural surroundings. Walzer claims that distributive justice is inextricably tied to the shared meanings of a community because it has to do with the allocation of social goods such as food, wealth, education and health care provision, whose meanings differ considerably from one community to another. All discussion of social justice, Walzer claims, 'will be idiomatic in its language, particularist in its cultural reference . . . historically dependent and factually detailed' ${ }^{27}$

Justice can be determined in a particular society by interpreting for its members the shared meanings of the goods distributed among themselves. Once the shared meaning of a good is ascertained, criteria for its distribution follow as a matter of course. Barry calls Walzer's theory conventionalism. ${ }^{28}$ If we were to take the globe as our site of justice we would have to invent the shared meanings for this imagined community. ${ }^{29}$ Ironically, this is the very accusation that Dworkin levels at Walzer in relation to interpreting the meanings of American Society. With regard to health care, for example, Walzer is accused of inventing what Americans think. Far from the democratic socialism attributed by Walzer to Americans, they favour only a basic minimum and emergency treatment as a welfare provision. ${ }^{30}$ Furthermore, the absence of shared meanings at the global level is just as much a feature of the domestic scene as it is of the international, and if justice were to hinge on such a consensus of meanings, then there is no place for it inside or outside of state borders.

On the question of whether current resource distributions constitute international injustice, Walzer wants to rely for the criterion upon culpable harm being perpetrated by past interventions, rather than upon a universal principle of redistributive justice. External responsibility for internal ills, arising from such actions as political control of trade, imperial wars, and the like, constitute international injustices which may require large-scale redistribution of resources. Where serious suffering and inequality exist, but which is not the consequence of some form of intervention, similar redistributions may be necessary, but they 
would not be a matter of justice. Justice does not, in Walzer's view and in harmony with Gordon Graham, exhaust morality, and ordinary principles of humane treatment and compassion may impel us to act out of charity rather than justice. ${ }^{31}$

Walzer, does not, however, want to abandon completely the idea of minimum universal standards of human rights based upon a thin universalism. In Spheres of_Justice Walzer clearly denies the existence of universal principles of justice. Walzer refuses to ground our ordinary notions of justice in such fundamental principles as equal treatment, desert or inalienable rights. By the time he wrote 'Interpretation and Social Criticism' (1988) and 'Nation and Universe' (1989), Walzer appeared to have change his mind in suggesting that killing, torture and deception were universally unacceptable, and evident universal consensus on such issues constitutes a minimal code of justice. ${ }^{32}$ However, he had already posited something like a minimum code of morality in Just and Unjust Wars (1977) some years earlier when he claimed that part of what we mean by being human is to have a right to life and liberty, whether natural or invented. They are features of our moral landscape. ${ }^{33}$ He claims not to create a new morality regarding just war, but to identify the shared meanings that are globally acknowledged.

Walzer distinguishes between the covering law type of universalism, which gives priority to a way of life as uniquely right, and which can be used as the basis for imperialist arguments, and reiterative universalism, which accepts that subject to minimal universal constraints there are many different and valuable ways of life that have equal rights to flourish in their respective locations, and deserve equal respect to our own. These universal elements are learnt through diverse experiences, but he denies that there is a common substance. They are overlapping sets of values which have family resemblances, but which are nevertheless products of the particularity of historical moral worlds. This is the point that Walzer is making when he argues that maximal morality, the type embedded in our societies and social practices, precedes universal minimal morality, which is in fact abstracted from the former. ${ }^{34}$

This minimum international morality amounts to the principles of selfdetermination (non-intervention), non-aggression and pluralism (the accommodation of tribalism within borders). Walzer's fundamental point is that the international community regards infringements of territorial and political sovereignty as self-evidently wrong. Sovereign integrity is ensured by the internationally accepted right of non-intervention which is analogous to the moral right of the individual to self-determination. Any infringements would therefore require extra-ordinary circumstances and special justifications. Given that the rationale of a state in his view is the protection of individual rights, particularly human rights, only gross infringements on a significant scale, for example genocide, would justify intervention if there are 'reasonable expectations of success' ${ }^{35}$ In such circumstances, a state falls significantly below what the idea of statehood requires, and breaches the trust endowed upon it by its citizens in 
some form of social contract. Walzer's argument brings clearly into relief the fundamental clash between the settled norms of sovereignty and those of human rights: the first prioritise the state and its moral relevance, and the second the individual whose moral status is often in conflict with that of the state. ${ }^{36}$

\section{Overcoming universalism versus particularism - O'Neill}

There are many arguments which link human rights with basic needs, and affirm an obligation to help the poor based upon these rights. Onora O'Neill, however, wants to move away from such associations posited by, among others, Henry Shue and Alan Gerwith. She wants to maintain that helping those in need is a matter of virtue and obligation but not of right or recht. She is critical of communitarians because their particularism and norm-orientated practical reason are relativistic and cannot provide the principles for international justice in an obviously interdependent world. Cosmopolitans or universalists are defective because they begin by assuming idealised starting points 'satisfied only by hypothetical agents whose cognitive and volitional capacities human beings lack'. ${ }^{37}$

O'Neill has argued that modern writers on ethics have tended to sever the traditional connection between justice and virtue. She associates cosmopolitans, or universalists, with arguing the case for justice, and communitarians with propounding a constitutive and embedded view of the virtues. What is crucial for her is the distinction between perfect and imperfect obligations. O'Neill's distinction rests upon the idea that perfect obligations are those which have determinate correlative rights and right-holders, whereas imperfect obligations differ in structure in that they have no correlative rights attached to them. In her view, this feature makes them no less obligatory. Those theories that make rights the fundamental ethical category, and which therefore rely heavily upon the notion of acts of recipience, find it difficult to justify as good or obligatory other acttypes which cannot be claimed as of right. Thus the virtue of charity is deemed supererogatory, that is beyond what is regarded obligatory, and therefore in the realm of discretion, because it has no correlative right attached to it. The virtue of charity has, therefore, almost become a pejorative term in the vocabulary of rights based ethical theorists. O'Neill argues that such theorists, including Rawls, have tended to assume that all obligations have correlative rights.

O'Neill's response to such views is to acknowledge that it is not feasible to rely on the social virtues to discharge the functions of social justice. It is a justifiable fear that unless rights to certain goods and services can be established then the weak and vulnerable are thrown onto the mercy of the good will of others which is all too often absent. She acknowledges that it is necessary to have institutions which establish rights and responsibilities in order to protect the vulnerable from systematic and gratuitous injury. To show that social virtues, such as charitableness, compassion, pity and generosity of spirit, cannot in themselves adequately protect the vulnerable and cannot therefore take the place of 
social justice, does not make them redundant. There may still be a whole range of required and necessary action that is not itself a matter of justice or claimable as a right. ${ }^{38}$

Justice is a matter of perfect obligation. Its requirements fall upon everyone and are matched by correlative rights. Virtues, by contrast, are a matter of imperfect obligation. Their requirements fall upon everyone, but specify no one as their recipients. Can principles of virtue, like principles of justice, also be inclusive or are they always embedded in situations? As with justice there must be certain principles of virtue which connect, or act as a manifold, for the different spheres of activity in which an agent moves in the world: 'The spheres of action must be linked not only by public institutions that co-ordinate or subordinate them, but by continuities of character which support continuities of activity, including feeling, relationships and community'. ${ }^{39}$ Without some consistency of character in different situations, life would be erratic and unpredictable, and the basis for trust and sustainable relationships would be eroded. O'Neill's point is that virtues are inextricably related to justice and must be embodied not only in individuals but also in institutions, traditions and the common culture of social groups. Institutions established on principles of justice cannot be sustained for long if they operate in a culture of corruption. The virtues of justice such as fairness, reciprocal respect, truthfulness, probity and fidelity are essential to the maintenance of just institutions both domestically and internationally.

\section{Conclusion}

In conclusion, then, there is as great a variety of responses to the question of international distributive justice from the perspective of special rights and obligations generated by communal ties of patriotism or nationality, as there are universalist claims. Where they differ, in general, is not in denying universal claims, but in suggesting that these claims have their basis and source in the thick morality, to use Walzer's words, of embedded communities. The particularist and the universalist is just as likely, however, to have the same goal of expanding the moral community to encompass the whole world, without resorting to an institutional cosmopolitanism. We are talking about differences in degree, and not in kind, depending upon from which end of the continuum one begins. For instance, Beitz, Barry and O'Neill are perfectly aware that our sense of justice and obligation does not extend very far beyond the borders of our states as things currently stand. They are concerned to show, on the basis of universal principles, how we have such obligations to others beyond our borders, and how, given existing institutional arrangements, they may be modified better to fulfil those obligations. What is particularly interesting about O'Neill's argument is that she readily acknowledges that the development of institutions to eliminate as far as possible avoidable systematic and gratuitous injury can very rarely come about de novo. Conceptions of reform and the will to make 
changes more often than not build upon current institutions and traditions. It is a matter of modifying what is to hand, redesigning parts rather than the whole, and re-establishing relations that have become disengaged. The purpose is to shape institutions in such a way that they better embody abstract principles of justice. ${ }^{40}$

The cosmopolitan who takes the individual as the subject of a universal moral law, what Beitz calls moral or ethical cosmopolitanism, is not thereby committed to an institutional cosmopolitanism. ${ }^{41}$ The key idea here as Pogge suggests 'is that every human being has a global stature as an ultimate unit of moral concern' ${ }^{42}$ The idea of a global moral community of humanity does not logically preclude the division of the world into smaller administratively manageable units, in whatever political form may be deemed most appropriate; states, federations, empires. Typically in the modern era that unit has been the sovereign state often coinciding with a desire on the part of a community for national self-determination. The point that the Natural Law theorist and modern cosmopolitans such as Barry and Goodin, and cosmopolitan Marxists would want to make is that the division is not absolute and that states are merely more or less convenient administrative apparatuses to sustain the purported common good of the communities they serve. Together these states in co-operation with each other serve the common good of humanity. In such a view there is an overlaying of responsibilities, laws, rights and obligations, and at some point a conflict of duties may arise between one's obligations as a citizen and as a person. Kant's cosmopolitanism, for instance, is fully cognisant of the existence of a primordial community of humankind and of the impracticality of a world state. The best that could be hoped for was a peaceful federation of states. A modern Kantian ethical cosmopolitan, such as O'Neill, acknowledges that nationality and other forms of community have an importance, and securing a national state may be instrumental in achieving justice for some, as for example looks to be the case with the Kurds. Yet the achievement of a national state may be just as likely to be the instrument of injustice to others, as the nationality problem in the former Soviet Union testifies. ${ }^{43}$

\section{Notes}

1 C. Brown, International Relations Theory (London, Harvester Wheatsheaf, 1992); J. Thompson, Justice and World Order (London, Routledge, 1992); C. Jones, Global Justice: Defending Cosmopolitanism (Oxford, Oxford University Press, 1999); P. Sutch, Ethics and International Justice (London, Routledge, 2001).

2 Brown, International Relations Theory, pp. 23-51.

3 C. Brown (ed.), Political Restructuring in Europe (London, Routledge, 1994), p. 173; M. Frost, Ethics in International Relatons: A Constitutive Theory (Cambridge, Cambridge University Press, 1996).

4 P. Singer, 'Famine, Affluence and Morality', Philosophy and Public Affairs, 1 (1971), pp. 229-243: P. Singer, 'The Singer Solution to World Poverty', New York Times, 5 September 1999. 
5 Singer, 'Famine, Affluence and Morality', p. 232.

6 G. Graham, Ethics and International Relations (Oxford, Blackwell, 1997), p. 136.

7 Singer, 'Famine, Affluence and Morality', pp. 231-2.

8 R.M Hare, Essays on Political Morality (Oxford, Clarendon Press, 1989), p. 3.

9 G. Hardin, 'Lifeboat Ethics: The Case Against Helping the Poor', Psychology Today, 8 (1974), pp. 38-43.

10 N. Dower, 'World Poverty', in P. Singer (ed.), A Companion to Ethics (Oxford, Blackwell, 1993), pp. 273-84.

11 Graham, Ethics and International Relations, pp. 152-5.

12 B. Barry, 'Humanity and Justice in Global Perspective', in B. Barry, Liberty and Justice (Oxford, Clarendon Press, 1991), pp. 186-7.

13 Barry, 'Humanity and Justice in Global Perspective', p. 207.

14 Cf. H. Shue, 'Morality, Politics and Humanitarian Assistance', in B. Nichols and G. Loescher (eds), The Moral Nation: Humanitarianism and U.S. Foreign Policy Today (Notre Dame, University of Notre Dame Press, 1989), pp. 14-16, and Jones, Global Justice, p. 13.

15 C. Beitz, Political Theory and International Relations (Princeton, NJ, Princeton University Press, 1979), pp. 136-43.

16 J. Rawls, The Law of Peoples (Cambridge, MA, Harvard University Press, 1999), p. 117.

17 Beitz, Political Theory and International Relations, p. 149.

18 Beitz, Political Theory and International Relations, and T. Pogge, Cosmopolitanism and Sovereignty', in Political Restructuring in Europe, ed. C. Brown (London, Routledge, 1994).

19 Rawls, The Law of Peoples, p. 116.

20 Rawls, The Law of Peoples, p. 117.

21 H. Steiner, 'Territorial Justice', in S. Caney, D. George and P. Jones (eds), National Rights, International Obligations (Boulder, CO, Westview Press, 1996), p. 45 (original emphasis).

22 Rawls, The Law of Peoples, p. 79.

23 C. Taylor, 'Conditions of an Unforced Consensus on Human Rights', in J. Bauer and D.A. Bell (eds), The East Asian Challenge for Human Rights (Cambridge, Cambridge University Press, 1999), p. 124.

24 Rawls, The Law of Peoples, pp. 65 and 79.

25 Rawls, The Law of Peoples, p. 80.

26 D. Miller, 'The Ethical Significance of Nationality', Ethics, 98 (1988), pp. 661-2.

27 M. Walzer, Spheres of Justice: A Defence of Pluralism and Equality (Oxford, Blackwell, 1983), pp. 21-2.

28 B. Barry, 'Spherical Justice and Global Injustice', in D. Miller and M. Walzer (eds), Pluralism, Justice and Equality (Oxford, Oxford University Press, 1995), p. 75.

29 Walzer, Spheres of Justice, pp. 29-30.

30 M. Walzer and R. Dworkin (1983), 'Spheres of Justice, an Exchange', New York Review of Books, 21 July 1983, pp. 43-6.

31 M. Walzer 'Response', in D. Miller and M. Walzer (eds) Pluralism, Justice and Equality (Oxford, Oxford University Press, 1995), pp. 292-3.

32 M. Walzer, 'Interpretation and Social Criticism', in S.M. McMurrin (ed.) The Tanner Lectures on Human Values (Salt Lake City, UT, University of Utah Press, 1988), and M. Walzer, 'Nation and Universe', in G.B. Petersen (ed.) The Tanner Lectures on Human Values (Salt Lake City, UT, University of Utah Press, 1989). 
33 M. Walzer, Just and Unjust Wars (first published 1977) (New York, Basic Books, 1992, 2nd edn), p. 54.

34 M. Walzer, Thick and Thin (Notre Dame, University of Notre Dame Press, 1994), p. 13.

35 Walzer, Just and Unjust Wars, p. 107.

36 Frost, Ethics in International Relations.

37 O. O'Neill, 'Abstraction, Idealization and Ideology in Ethics', in J. Evans (ed.), Moral Philosophy and Contemporary Problems (Cambridge, Cambridge University Press, 1987). For a very good critical appraisal of O'Neill's position see Sutch, Ethics, Justice and International Relations, pp. 85-113.

38 O. O'Neill, Towards Justice and Virtue: A Constructivist Account of Practical Reasoning (Cambridge, Cambridge University Press, 1996), p. 190.

39 O'Neill, Towards Justice and Virtue, p. 172.

40 O'Neill, Towards Justice and Virtue, pp. 182-3.

41 C. Beitz, 'Cosmopolitan Liberalism and the States System', in C. Brown (ed.) Political Restructuring in Europe (London, Routledge, 1994), pp. 124-5.

42 Pogge, 'Cosmopolitanism and Sovereignty', p. 90.

43 O'Neill, Towards Justice and Virtue, pp. 78-9. 